\title{
A New Algorithm for Protection of Small Scale Synchronous Generators against Transient Instability
}

\author{
Zinat Khosravi*, Alireza Saffarian \\ Shahid Chamran University of Ahvaz \\ *Corresponding author, e-mail: z.khosravi67@yahoo.com
}

\begin{abstract}
Today, installation of small generators has been increased because of their considerable benefits in distribution systems in distributed generation. One of the most important problems for transient stability is the effects of the faults of system. Small scale generators have low constant inertia and protection relays have slow performance in distribution systems. Therefore transient instability is a probable phenomenon for the systems with these generators. In this paper, dynamic response of generator has been studied in different fault conditions and then by introducing the concept of "critical fault clearing time ", the sensitivity of this time to the fault type and also fault location parameters have been studied. Then a new protection scheme has been proposed to prevent of transient instability for small scale generator. This protection scheme uses a new evolutionary algorithm based on the active power of generator and critical fault clearing time. The proposed relay can prevent of wrong and unwanted performance. Furthermore it can disconnect the generator from the system in three phase fault near of the bus-bar before its instability. Simulation results show reliable performance of the proposed relay against system transients.
\end{abstract}

Keywords: distributed generation, small scale synchronous machine, critical clearing fault time, out of synchronism

Copyright $\odot 2015$ Institute of Advanced Engineering and Science. All rights reserved.

\section{Introduction}

Distributed generation (DG) is a power supply that is directly connected to the network. Today, installation of DGs has been increased because of many advantages like loss reduction, improvement in load losses and load peaks, auxiliary services and better power quality [1]. This power sources cause some changes for distribution systems and can create instability and move the network to exit in some cases [2,3]. DGs are mainly synchronous machines. For a synchronous generator (SG) there is a maximum rotor angle that DG has a stable operation for below of this angle. Fault clearing time and inertia have important effects on SG stability. Fault clearing time for transmission system is approximately $100 \mathrm{~ms}$, but this time is longer for distribution system. Furthermore, inertia constant for small scale SGs is usually below $2 \mathrm{~s}$ that is small with respect to large scale SGs which is 3 to $5 \mathrm{~s}$ [4]. Transient instability is a main concern for large scale generators because of reasons like low inertia constant and slow operation of protection relays. Therefore, this problem is very serious for connected Small Scale protection of Synchronous Generators (SSSGs). So more careful studies are necessary to analysis of dynamic behavior of these generators against faults. Caldonand et.al., have studied dynamic behavior of based inverter DGs at the presence of disturbances. This reference believes that connection of DGs using inverter can eliminate resulted problems from fault current feeding of the generator and its instability. Supplying of the fault current via this DGs increases the maximum injected power without changing of network structure [5]. Reference [6] have investigated the transient instability in distribution systems considering DGs with production of power and heat, micro-turbine and wind turbine simultaneously. This ref. has concluded that inertia constant of micro-turbine is the most effective parameter in transient stability. Also, outage of large DGs disturbs the equality between active and reactive power and causes many problems during fault occurrence. So, appropriate settings for protection relays in the connected DGs are very important [6]. Using of a skidder series resistance for improvement of transient stability with small inertia constant has been proposed in [7]. This ref. has claimed that this resistance has great effect on transient stability and can prevent occured faults near to generator. Reference [14] studies the effect of fault on DG stability. This ref. claims that under 
voltage (UV) relays has a setting as 0.8 p.u. and $2 \mathrm{~ms}$ which these amounts are function of the interconnection relays. This is probable that a large scale DGs go to outage in fault condition. Therefore, an appropriate setting for UV relays is necessary to meet the requirements of fault ride through (FRT) [8]. The effect of fault clearing time on DG stability is studied in [9] and this is recommended that all main settings must be done to prevent of DG instability. Furthermore this is claimed that the setting for UV relays must be performed based on transient stability studies. In the present paper, a new method has been proposed to detect of outage from synchronism for SSSG. This method can prevent the instable operation of generators and increases the availability of DGs. In other words, a new relay is proposed to solute of the mentioned problems in other studies. This method is performed on two steps. First step: in this step, dynamic behavior of SSSG against the faults is analyzed and then a sensitivity analysis for generator transient stability is done on the parameters including fault type and its location. In this step a real $63 / 20 \mathrm{kV}$ substation with three small scale generator is used. These generators have been connected to a $20 \mathrm{kV}$ busbar via three transformers [10]. Second step: in this step a new based active power algorithm is proposed that its inputs are measured three phase currents and voltages at the terminal of SSSG with the frequency sampling of $1 \mathrm{kHz}$. Algorithm is based on the amount of produced active power during fault. This calculated power has a major fluctuations which have a main role in the relay operation time. [10]. Study in the field of small scale generator and its response against the faults of system, has a limited references.

\section{Transient Stability of SSSG}

In this section, at first dynamic behavior of SSSG against system faults is analyzed. Then, the sensitivity analysis for generator transient stability is performed with system parameters including fault type and its location.

\subsection{System Modeling}

In this study a real network including three SSSG has been simulated in DIgSILENT. These generators have been connected to a $20 \mathrm{kV}$ busbar via three interconnection transformers. These transformers have a earthed $Y-\Delta$ vector group which is a proper connection for interconnection transformers. Generator's neutral have been earthed via a resistance for limitation of the earth-fault current. Output feeders include air line and cables to consider all probable study conditions. A $63 \mathrm{kV}$ network has been modeled as an external network by its Thevenin equivalent model. The studied network has been shown in Figure1.

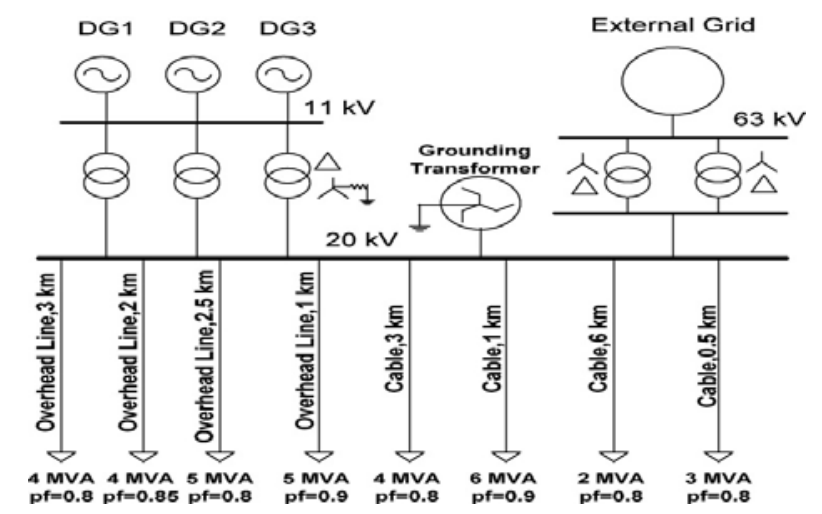

Figure 1. Single line diagram for studied network

\subsection{Fault clearing time curve with respect to fault type and location}

For determination of critical clearing time (CCT), some simulations should be done by different fault times. First, a simulation is done with a long duration approximately 2 second. If system can remain in stable condition, fault duration is decreased with an acceptable time step. First time that transient instability occurs, is presented as CCT. In this section, CCT is calculated for different faults with different locations during the 3 kilometer of output airline. 


\subsubsection{Fault Clearing Time for Three Phase Fault at Busbar}

Here, a three phase fault occurs at $20 \mathrm{kV}$ busbar at $\mathrm{t}=100 \mathrm{~ms}$ and is cleaned at $\mathrm{t}=$ $262 \mathrm{~ms}$. From Figure 2 it is obvious that the speed of generator increases during fault and reaches again to its nominal value. From out of synchronism curve this is found that generator is not instable. The curves of power factor, current, active and reactive power and voltage terminal have been shown in Figure 3 These figs shows that active power of generator decreases extremely because of extreme deep of voltage bus and after fault clearing, increases and reaches to its nominal value.

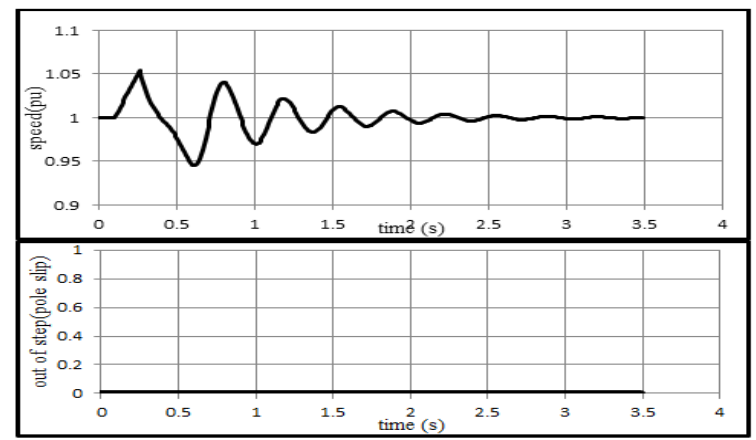

Figure 2. speed and out of synchronism curves at three phase fault at $\mathrm{t}=100 \mathrm{~ms}$ and critical fault time

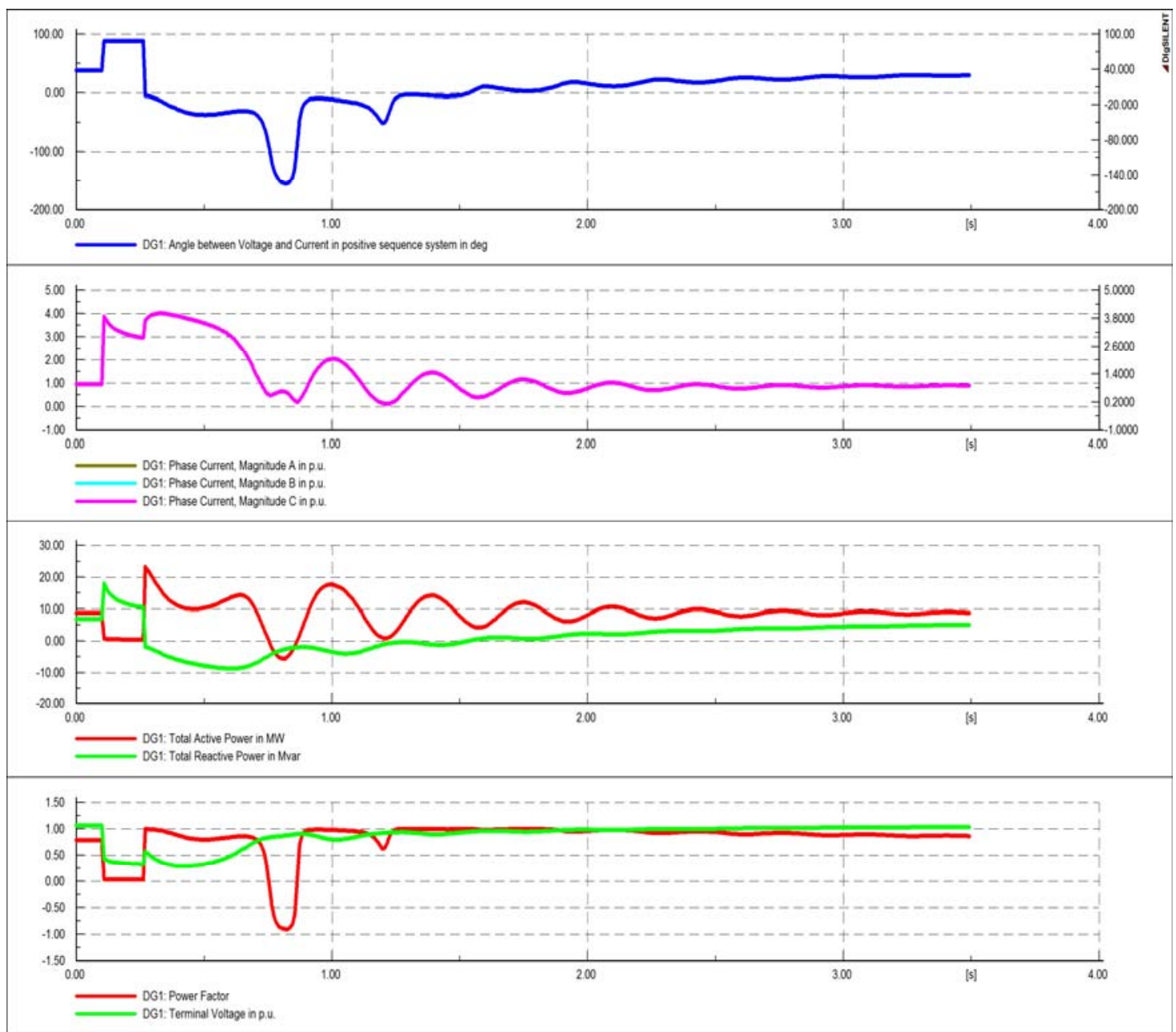

Figure 3. The curves of power factor, current, active and reactive power and voltage terminal at three phase fault at busbur at $\mathrm{t}=100 \mathrm{~ms}$ and at fault clearing time $162 \mathrm{~ms}$

TELKOMNIKA Vol. 16, No. 3, December 2015: $454-462$ 
Figure 4 is power-angle curve (swing curve). From this figure this is found that output active power deeps extremely when a fault occurs and reaches to an instantaneous increment after fault clearance. To show stability, P0 has been drawn by a bold horizontal line as primary work point. Rotor angle and primary active power points are available and therefore maximum transferring power and sinusoidal equation of power can be achieved. Swing curve has also been drawn from simulation of generator during fault. It is found that the surface $A 1$ is smaller than A2. Therefore, because mechanical power is constant, rotor angle has not large increment and is stable at the $t=162 \mathrm{~ms}$ fault.

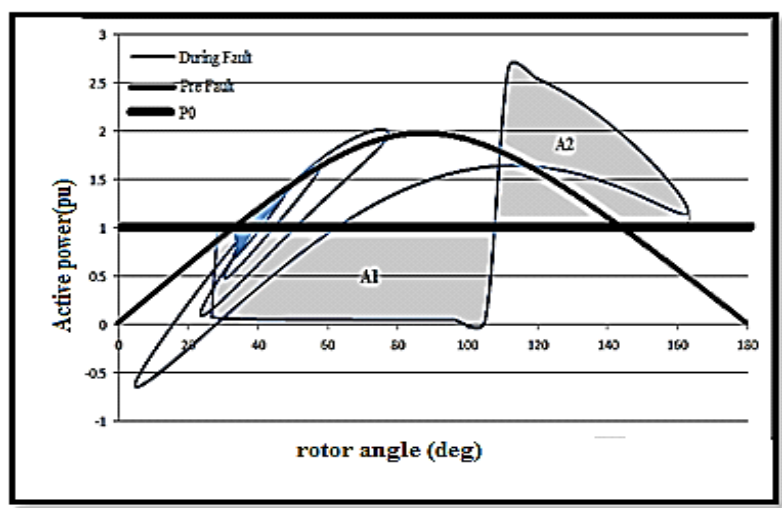

Figure 4. Swing curve at three phase fault at busbar at $t=100 \mathrm{~ms}$ and clearing fault time $t=162$ $\mathrm{ms}$

At Next step a three phase fault is simulated at busbar $20 \mathrm{kV}$ at $\mathrm{t}=100 \mathrm{~ms}$ and is removed at $\mathrm{t}=263 \mathrm{~ms}$. Figure 5 shows that the speed of fault increases during both fault and after it and the out of synchronism curve is turned and therefore generator goes to instability. The curves of power factor, current, active and reactive power and voltage terminal have been shown in Figure 6 This figure shows that active power of generator extremely decreases because of extreme deep of voltage bus.

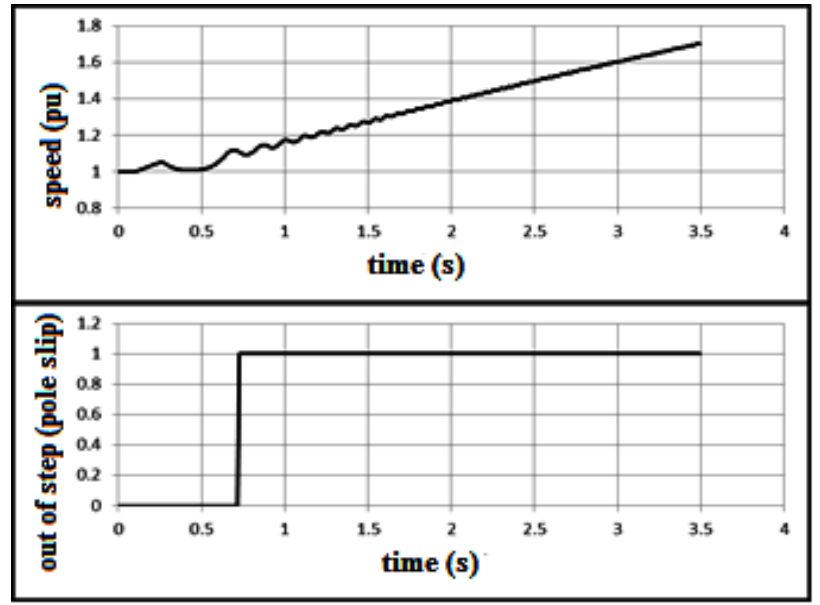

Figure 5. Speed and out of synchronism curves at three phase fault at busbar at $\mathrm{t}=100 \mathrm{~ms}$ and fault clearing time $163 \mathrm{~ms}$ 


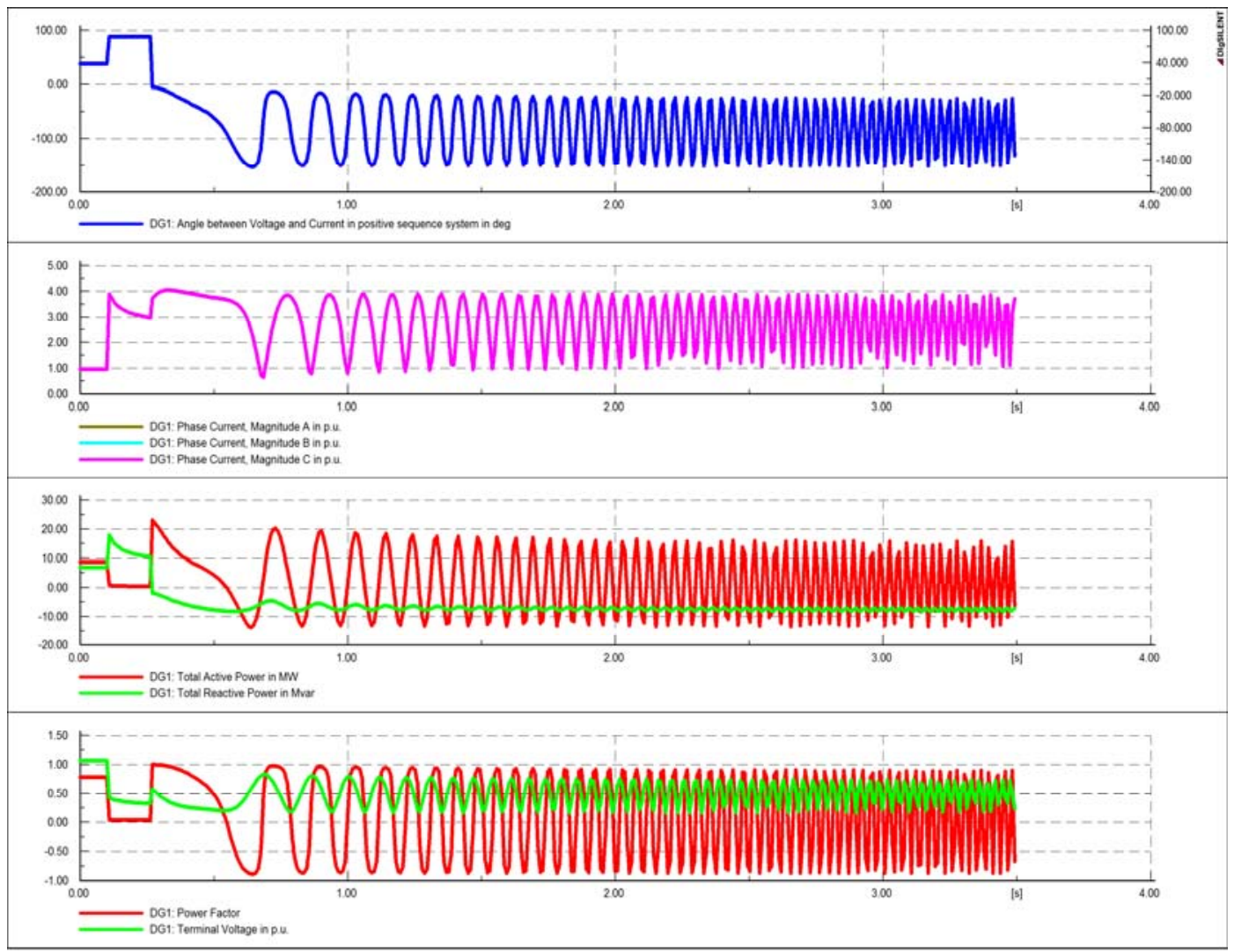

Figure 6. The curves of power factor, current, active and reactive power and voltage terminal at three phase fault at busbur at $\mathrm{t}=100 \mathrm{~ms}$ and at fault clearing time $163 \mathrm{~ms}$

Figure 7 is swing curve in fault time $163 \mathrm{~ms}$. If the mechanical input power is constant, extra energy will convert to kinetic energy and rotor will accelerate. Therefore the reserve kinetic energy during fault will be larger than the lost energy after fault and rotor acceleration continues. From swing curve this is obvious that generator outs from synchronism and will be instable.

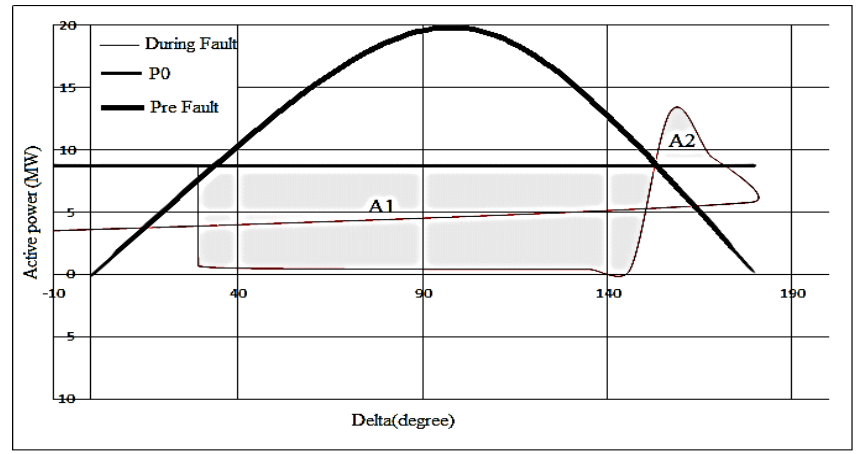

Figure 7. Swing curve at three phase fault at busbar at $t=100 \mathrm{~ms}$ and clearing fault time $\mathrm{t}=163$ $\mathrm{ms}$

\section{The Proposed Protection Scheme}

The critical fault clearing time for phase to phase and three phase faults is very larger than others. Therefore in the case of these faults, the network has adequate time for disconnection of faulted feeder before transient instability of SSG and this is not necessary that 
generator be disconnected rapidly. The proposed protection scheme must remove the faults according to their importance from the view point of stability. The proposed scheme is based on equality surface criterion. In other words, generator stability depends on its output active power during of fault. By this criterion, if the transferred active power is larger during fault, the accelerating surface will smaller and rotor will have less energy and fluctuation amounts. Therefore, the transferred active power during fault can be a proper index for prediction of instability. Figure 8 shows the active power of one of the generators at phase to phase and three phase faults at busbar at $\mathrm{t}=100 \mathrm{~ms}$ and their clearance at $\mathrm{t}=250 \mathrm{~ms}$. Figure expresses that active power has been extremely decreased and active power rapidly changes during fault and active power reduction for two phase fault is smaller than the same three phase fault.

Figure 8. Active power at phase to phase and three phase faults

Therefore, this is possible that by active power as the input of relay, fault location and fault type be determined. If the critical clearing time and active power be calculated at three phase fault at various locations and on output air feeder, CCT curve will be obtained (Figure 433) that results determination of fault location. Because of delay in calculation of active power and transients in voltage and currents in different faults, active power has been considered as criterion for $50 \mathrm{~ms}$ after fault occurrence. Active power in p.u. is based on apparent power of generator. CCT curve at $\mathrm{P}$ for theses faults has been shown in Figure 9.

Figure 9. CCT curve at $\mathrm{P}$ at three phase fault with different location on busbar

More CCT and more transmitted active power are corresponding to farther faults. Therefore, there is adequate time for disconnection of generators before they can result instability. This is adaptable with FRT requirements. The obtained curve for determination of proper operating time of relay based on fault location is employed before transient instability of SSSG. A proper inverse characteristic curve should be selected for relay. By considering of operating time and also safe time margin to increase the security factor, $100 \mathrm{~ms}$ has been used in fig for safe time margin between relay characteristic and CCT-P 10. The proposed relay characteristic in Figure 4-34 can be converted to Equation (1) with an acceptable error.

$$
\text { Top }=802.41 p^{2}-215.53 p+80.32
$$

Figure 10. Characteristic curve for the proposed relay

\section{Algorithm}

The measured three phase currents and voltages are the inputs of SSSG terminals with sampling frequency of $1 \mathrm{kHz}$. Algorithm is based on the output active power during fault. All current and voltage phasors should be calculated and therefore total active power can be achieved. This active power has fluctuations that have not considerable effect on time operating of relay. Hence this is a simple and capable method for calculation of active power. To prevent of operation in the transients like load shedding, which can result some power fluctuations, the range of operation has been limited to smaller than 0.8 p.u. values. These fluctuations can threat the safe operation. Considering these points, the limited safe operation range is achieved. This method is shown in Figure 11 [10]. 


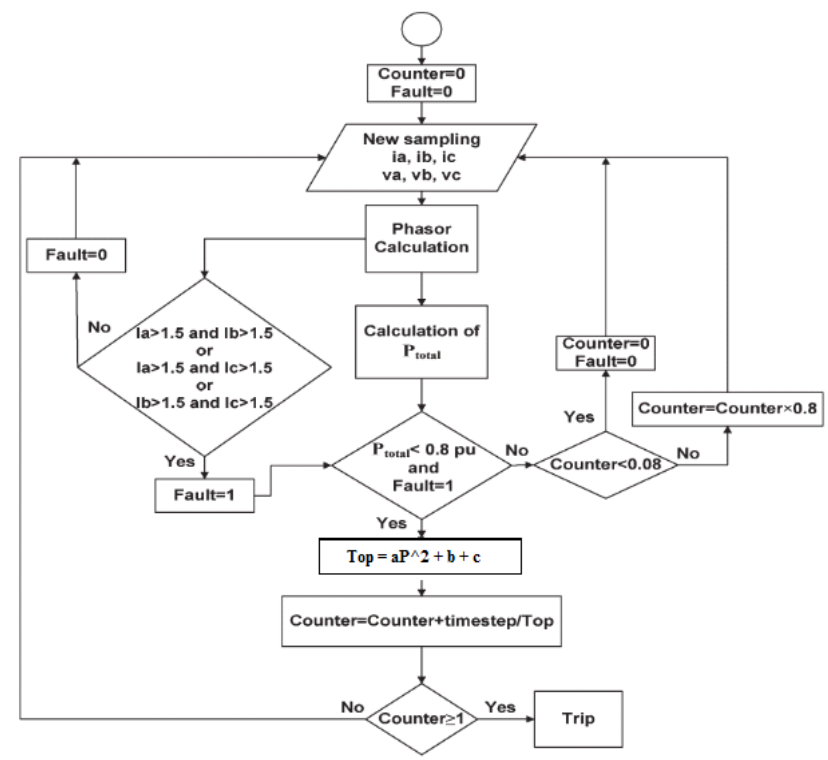

Figure 11. Flowchart for the proposed algorithm

To increase of the safety, three phase current phasors have been used in load shedding for prevention of relay operation. This is based on this fact that if current was larger than 1.5 p.u. in two phases, fault should occur and otherwise, relay has no action (relay has been closed). This claim is true because load changes can not cause that generator current be larger than 1.5 p.u. The fault detection logic actives the relay. If calculated power is lower than 0.8 p.u., time operation will be calculated and relay counter will be increased from characteristic curve in Figure 9.

\section{Operating Results of the Proposed Relay}

The power system with single line diagram in Figure 3-1 has been chosen to test the operation of the proposed relay. For three phase faults in different locations on a 3 kilometer air feeder, phase to phase and single phase faults at busbar $20 \mathrm{kV}$, generator disconnection time which is equal to operation time of the relay in addition of $80 \mathrm{~ms}$ to consider of time operation of breaker, have been shown in Table 1.

Table 1. Results for relay operation

\begin{tabular}{ccc}
\hline Fault type - fault location & $\begin{array}{c}\text { Sepration time of generator } \\
\text { by proposed relay }(\mathrm{ms})\end{array}$ & cct $(\mathrm{ms})$ \\
\hline Single phase - busbar & No operation & stable \\
Phase to phase - busbar & No operation & 960 \\
Three phase - busbar & 142 & 162 \\
Three phase $-0.3 \mathrm{~km}$ & 156 & 178 \\
Three phase $-0.6 \mathrm{~km}$ & 175 & 198 \\
Three phase $-0.9 \mathrm{~km}$ & 208 & 221 \\
Three phase $-0.12 \mathrm{~km}$ & 237 & 246 \\
Three phase $-0.15 \mathrm{~km}$ & 264 & 275 \\
Three phase $-0.18 \mathrm{~km}$ & 301 & 311 \\
Three phase $-0.21 \mathrm{~km}$ & 311 & 354 \\
Three phase $-0.24 \mathrm{~km}$ & 361 & 411 \\
Three phase $-0.27 \mathrm{~km}$ & 142 & 492 \\
Three phase $-3 \mathrm{~km}$ & & 624 \\
\hline
\end{tabular}

Considering the setting of $250 \mathrm{~ms}$ for voltage relay accordance with standards, the proposed relay has much better operation. Because critical fault clearing time has been determined $162 \mathrm{~ms}$ and relay disconnects generator when it is instable. Critical fault clearing

TELKOMNIKA Vol. 16, No. 3, December 2015 : $454-462$ 
time is $960 \mathrm{~ms}$ for two phase fault at busbar, voltage relay disconnects generator at $\mathrm{t}=160 \mathrm{~ms}$ that there is no necessary need for rapid disconnection. For three phase fault also there is no necessary need for rapid disconnection and the proposed relay can increase the availability duration of generator and prevent from its unwanted outage. In the case of three phase faults at $\% 20$ of the end of feeder, relay has no operation because active power is larger than 0.8 p.u. during these faults. For protection of generator against this faults and also phase to phase faults, can employ other available relays like voltage relays with higher settings and relays with more delay time. The results show that for all studied cases, fault clearing time is smaller than critical fault clearing time. Furthermore, for single phase and phase to phase and three phase faults at the end of line that do not create transient instability for generator, there is adequate time for fault clearance and prevent unwanted disconnection. For these faults, other protection relays protect the generator with adequate time delay. Some relays like under voltage relays, are used as a classic method to prevent transient instability [11]. But this is probable that generator be disconnected in unnecessary conditions like two phase and three phase faults [11]. This short clearing time makes miss coordination of UVs with downward system and for two phase and three phase faults results unwanted disconnection of generator and reduces its availability [12].

\section{Constancy of the Proposed Algorithm}

To test the constancy of the proposed algorithm in different operation conditions, several states have been considered. These conditions include change in the short circuit power of the external network, change in the number of generators and interconnection transformers. To test the safe operation of relay in these conditions this is adequate to observe some changes in relay characteristic curve.

Figure 4-35 shows the sensitivity of relay characteristic curve to these changes. This figure (2 transformers) corresponds to the case with one disconnected transformer. In second case (Zth change), three interconnection transformers are in the system and short circuit power of the external network has been increased. In other words, equivalent impedance of the external network has been decreased. Employing of curve fitting method for these curves can be expressed as Equation (2).

$$
\text { Top }=a p^{2}+b+c
$$

Table 2 shows approximate values for $\mathrm{a}, \mathrm{b}, \mathrm{c}$ and says these parameters do not create very changes in variable conditions. This is one advantage for the proposed relay that demonstrates its capability in various system and its conditions.

Table 2. Approximate values for $a, b, c$

\begin{tabular}{cccc}
\hline Change in condition & $\mathrm{a}$ & $\mathrm{b}$ & $\mathrm{c}$ \\
\hline SSSG 2 & 06.911 & -06.248 & 589.88 \\
SSSG 1 & 06.911 & -06.248 & 589.88 \\
Transformer 2 & 06.911 & -06.248 & 589.88 \\
Zth changed & 2.1112 & -378 & 99 \\
\hline
\end{tabular}

\subsection{Transient Effects on the Operation of Proposed Relay}

A secure protection scheme should operate carefully during transients. The proposed relay is mainly based on active power and therefore should not be affected by power fluctuations. In this section operation of proposed algorithm has been tested during transients. In this case, a large load shedding and transient fault have been simulated for system. All amount of active power has been shown in Figure 12 during this load shedding. This amount is larger than 0.8 p.u. Therefore, relay has no action. Figure 13 shows the counter amount for these transient faults. Counter increases during short circuit but resets rapidly. These results express that the proposed relay has a reliable operation against system transients. 
Figure 12. Active power for a large load shedding

Figure 13. Counter amount, activation of the relay and its disconnection signal for a transient fault

\section{Conclusion}

Today, installation of small generators has been increased because of their considerable benefits in distribution systems in distributed generation. One of the most important problems for transient stability is the effects of the faults of system. Small scale generators have low constant inertia and protection relays have slow performance in distribution systems. Therefore transient instability is a probable phenomenon for the systems with these generators. This paper offered a new method for detection the out of synchronism of the small scale generator. This method was based on equal surfaces criterion and employed active power for determination of instability and out of synchronism. This scheme can prevent of instable generator operation and increases the availability of distributed generations including synchronous generator. In other words a new relay has been proposed to solute the former problems.

\section{References}

[1] T Ackermann, G Andersson, L Söder. Distributed generation: A definition. Elect. ower Syst. Res. 2001; 57(3): 195-204.

[2] P Siano, LF Ochao, GP Harrison, A Piccolo. Assessing the strategic benefits of distributed generation ownership for DNOs. IET Gener. Transm. Distrib. 2009; 3(3): 225-236.

[3] J He, Y WeiLi, MS Munir. A flexible harmonic control approach through voltage-controlled DG-grid interfacing converters. IEEE Trans. Ind. Electron. 2012; 59(1): 444-455.

[4] W Freitas, JCM Vieira, A Morelato, LCP da Silva, VF da Costa, FAB Lemos. Comparative analysis between synchronous and induction machines for distributed generation applications. IEEE Trans. Power Syst. 2006; 21(1): 301-311.

[5] I Xyngi, A Ishchenko, M Popov, L van der Sluis. Transient stability analysis of a distribution network with distributed generators. IEEE Trans. Power Syst. 2009; 24(2): 1102-1104.

[6] I Xyngi, A Ishchenko, M Popov, L van der Sluis. Protection, transient stability and fault ride-through issues in distribution networks with dispersed generation. In Proc. 43rd Int. Univ. Power Eng. Conf. Padova, Italy. 2008: 1-5.

[7] R Caldon, F Rossetto, R Turri. Analysis of dynamic performance of dispersed generation connected through inverter to distribution networks. 17th International Conference on Electricity Distribution. Barcelona. 2003.

[8] A Ishchenko, JMA Myrzik, WL Kling. Transient stability analysis of a distribution network with distributed generators. Proceedings of the 41st Internathional Universities Power Engineering Conference. UK. 2006.

[9] RM Tumily, CG Bright, GM Burt. Applying series braking resistors to improve the transient stability of low interia synchronous distributed generators. $19^{\text {th }}$ International Conference on Electricity Distribution. Vienna. 2007.

[10] R Razzaghi, M Davarpanah, M Sanaye Pasand. A novel protective scheme to protect small scale synchronous generators againt transient instability. IEEE Trans. Ind. Electron. 2013; 60(4): 16591667.

[11] EJ Coster, JMA Myrzik, WL Kling. Influence of protection on transient stability of medium voltage grids including distributed generation. In Proc. Univ. Power Eng. Conf. England. 2007.

[12] SSW El-khattam, R Seethapathy. Comparison of anti-islanding schemes operating time for distributed systems with large capacity wind turbines. Fifteenth national power systems conference (NPSC). 2008. 